\title{
A Study of a Casual relationship between Performance Appraisal and Employee's Performance: Evidence from the Textile Sector in Faisalabad
}

\author{
${ }^{1}$ Dilbar Hassan Ch., ${ }^{2}$ Rakhshanda Maqsood, ${ }^{3}$ Snawer Gill \\ ${ }^{1}$ MS- Scholar (GCUF), Vice President, NBP, Corporate Banking Group, Pakistan \\ ${ }^{2}$ PhD- Scholar, Department of Sociology, Government College University, Faisalabad, Pakistan \\ ${ }^{3}$ MS- Scholar, Finance Manager, La Salle Brothers Pakistan
}

\begin{abstract}
Employee performance is the strength of the organization. This study relates to the assessment of the relationship between employee performance evaluations to assess the moderate role of motivation. The current research was conducted in Faisalabad's textile industry. A sample of 204 respondents was drawn using a convenient sampling technique. In addition, the primary information was collected through a questionnaire. For data analysis, SPSS (version-20) software applied percentage, mean, standard deviation, regression and correlation coefficient methods. The result is achievable in a positive relationship between the outcome of the conversion and the employee's earnings. Another variable is motivation, because the moderator has a positive effect between the two relationships. The textile industry can use the evaluation rule as a deliberate approach by integrating it into its business policy and HR practice and improving the employee's performance in the organization.
\end{abstract}

Keywords: Performance appraisal, employee's performance, Motivation, Regression, Correlation

\section{Introduction}

The most important thing for an organization is to maximize employee performance. The best organizational performance is related to the employee's satisfaction and motivation. The performance evaluation system starts in the 1940s, and this system justifies the estimate of earnings by employee loyalty(Boachie-Mensah \& Dogbe, 2011). The main problem in an organization tries to satisfy and motivate to do its best, and the performance evaluation is one of them. Thanks to the performance evaluation, the employees in the organization work best to achieve a good result. Employees are motivated when an organization assesses their performance and adjusts appropriately. Performance evaluation and work can have a moderate role in motivation. Growth and enthusiasm for employees, human resources, work planning and communication has different perspectives for defining an evaluation system for performance (Oraman, Unakitan, \& Selen, 2011). Motivation is a more productive position promoted by employees. Levy and Williams (2004) say performance is a procedure for assessing individual performance and improving performance and promoting organizational performance. Motivation is people's ability to develop behavior (Campbell, Campbell, \& Chia, 1998). After selecting employees, the most effective instrument leaders must review employee performance and achieve a performance evaluation (Barrick \& Mount, 1991). When assessing the performance of the employee, what the organization expects of the employees and how well they do to achieve good results (Honey, 2001). Performance evaluation serves as a feedback system that describes employee quality and work capacity. Evaluation is an integral part of the organization, which is the relevant purpose of evaluation and implements a practice of changing motivation (Judge \& Ilies, 2002). Pakistan has a number of textile industries that utilize performance-enhancing performance and translate into organizational performance. Performance evaluation is a very important process, but is considered "weak in the management of human energy" (Willis-Shattuck et al., 2008). So it's important to check the employees' efficient work (Asiabar, Biglar, Manesh, \& Moslehi, 2013). The strength of employee beliefs does not depend on your exclusive services that exceed the inspiration height of each show (Ali, Mahdi, \& Malihe, 2012). Embarrassment is an internal effort to create a technology to occupy the improvement of an organization (DiSanza \& Legge, 2016). Employee motivation is the level of engagement and participation of employees in the organization and its value.

Performance evaluation plays a key role in measuring employee performance and helps monitor progress towards hope and organizational objects (Boachie-Mensah \& Dogbe, 2011). In modern times, performance evaluation is an important tool for evaluation. As a result, the role of each employee in the organization is controlled under appropriate conditions. Performance Evaluation allows you to easily focus on employee 
performance to evaluate your daily performance and reward. Performance evaluation enables individual goals and is managed to achieve the organization's strategic goals.

\section{Performance Appraisal}

Appropriate evaluation structure or measurement of work using the scale and index as well as the management process from the assessment of a large number of researchers' credit rating in the last decades in the performance evaluation. Its sound is so simple, but the researchers have talked about behavioral results and identified the strengths and weaknesses of the individual (DeNisi \& Pritchard, 2006). In business and industry, earnings estimates are calculated between 74 and 89\% (Bowen \& Ostroff, 2004). Performance evaluation for different purposes with personnel decisions, evaluation and feedback. The activity was measured by comparing the results, which accurately estimated the desired amount and quality. Performance is the way in which employees perform their tasks and measure the outcome by evaluating effectiveness (Cawley, Keeping, \& Levy, 1998). The researcher says that the evaluation of individuals is an important aspect of disposition and perspective. Performance evaluation has three main goals in an organization where management, development and communication. Fletcher discussed the key role of maintaining a performance assessment system in the heart of the integrated HRM. The performance assessment evaluates efficiency in two perspectives, one of which monitors the efficiency and efficiency of the system from a managerial perspective, and examines the performance evaluation system from a subtle point of view.

Combs, Liu, Hall, and Ketchen (2006) suggested that the organization clarify the sources of business management should be concerned about an effective evaluation. Effective evaluation is used for various purposes, which gives employees the productivity and quality of work. In addition to motivating them to do better by giving them an appropriate assessment of their work. According to Levy and Williams, in order to change the traditional perception of performance evaluation, it was taken into account when establishing performance evaluation. Many researchers have found that employee response to performance evaluation is an important part of the assessment process because they can evaluate a better way of assessing feasibility than psychometric indices (Güngör, 2011). The right to performance evaluation has a major impact on organizational efficiency. Traditional and non-traditional techniques are used to evaluate performance. A traditional evaluation method is called "Free From Method", which includes monitoring and description of employee performance (Elicker, Levy, \& Hall, 2006). Non-traditional evaluation method used in modern times. In most cases, these techniques are used in the evaluation method. The assessment centre has internal arrangements and test targets for employees (Taticchi, Tonelli, \& Cagnazzo, 2010). A practical anchored rating scale finds the quality of the work. The method of calculating human resources estimates employee earnings. 360 degrees is related to feedback (Judge, Thoresen, Bono, \& Patton, 2001).

Employee's Performance: High staff performance is an important challenge for the organization and better opportunities for low-performing employees (Grubb, 2007). Performance is the organization of the organization whose work it is to do and do it well (Renwick, Redman, \& Maguire, 2013). The action that can be seen and measured is reflected in the performance. The organization needs high paid employees to achieve their goals and can also get a competitive edge (Jabeen, 2011). There is a big difference between work and performance. He is working on personal skills and the work is done after being exhibited. Presentations are not a basic technical message, but only a psychological environment to achieve the organization's goals. It refers to behavior, how to help colleagues and demonstrate a reliable member of the organization (Mani, 2002).

The development of the traditional course is emphasized and focuses on the personal features and characteristics of the work. According to Brumback, performance evaluation uses a number of questions, a brief written answer and a description of the staff to be submitted to the evaluator. Regular and correct use of services gives a better result to the organization. The two sides of the performances can be facial, negative and positive.

Motivation: Motivation is part of the maintenance and management of the employees' ways and behaviors. Kavanagh claims that the employees need freedom and characteristics for the work environment price creates motivation. Motivational work seeks to achieve the organization's goals (Kline \& Sulsky, 2009). 
Motivated employees are strongly involved in the highest employees. The qualities of self-sufficiency and freedom are present in motivated workers. In many countries, performance evaluation uses public service knowledge, what they expect, to describe their performance and performance. The organization must have motivated employees because they know the responsibility for the internship. Motivated workers are those who work clearly in accordance with the goals. It is the perception of a people who describe the intensity of behavior (Petri, 2004). Performance evaluation helps employees achieve goals, goals and guidance (Iqbal, Ahmad, Haider, \& Batool, 2013).

In this study, we make the context of evaluating the performance of this framework. The justice of the procedure implies the relative weighting of the basic part of the evaluation system. Distribution theory is related to the distribution of fairs. The reports concern fair conduct with the employees being performed. Harris claims that the employees are very vulnerable to their behavior and respect for themselves. Finally, knowledge-based law refers to performance prediction and standard explanation. The basic need for evaluation is objective and standard feedback of rules (Harris, 1994).

The implicit human theory is also associated with employee motivation. The researchers say that implicit theories are professional convictions that directly affect a person's behavior. Motivation is a privilege to operate in a unique target area. Performance evaluation is an effective role in developing employee trust in the organizational system. Employees who believe the outcome of the assessment is unfair often leaves organization and morale weaker. And it changes its behavior on the wrong things about the organization's costs.

In Pakistan, most performance evaluation programs are not well planned and focused. Evaluation of effectiveness cannot be beyond the emphasis of overall organization performance. Personal interpretation interprets the outcome of the evaluation with a fair result. The policies give a lot of employees a better effort. The impact of social recognition as an incentive has long been observed and recognized. The existence of a performance evaluation policy means employees who are interested in performing and developing an organization. It also has a positive impact on the individual's value, commitment and affiliation. Employee performance has attracted the attention of the professionals, so there are much evidence of performance evaluation and employee performance.

\section{Objectives}

$>$ To investigate the relationship between performance appraisal and employee's performance.

$>$ To analyze the effect of performance appraisal on motivation and employee performance.

Theoretical Framework: The organization's goals depend entirely on the employee's work plan. Performance assessment directly indicates employees and employees' expectations to be focused on the pilot. Employee evaluation is compared to the objectives during the evaluation period. The assessment shows employee performance what employees have achieved their goals. Regular assessment helps employees to focus their attention on what is expected to provide feedback to employees and motivation (William, 2010). Positive feedback shows that employees have done their job well and that the shortcomings have been improved.

\section{Conceptual Framework}

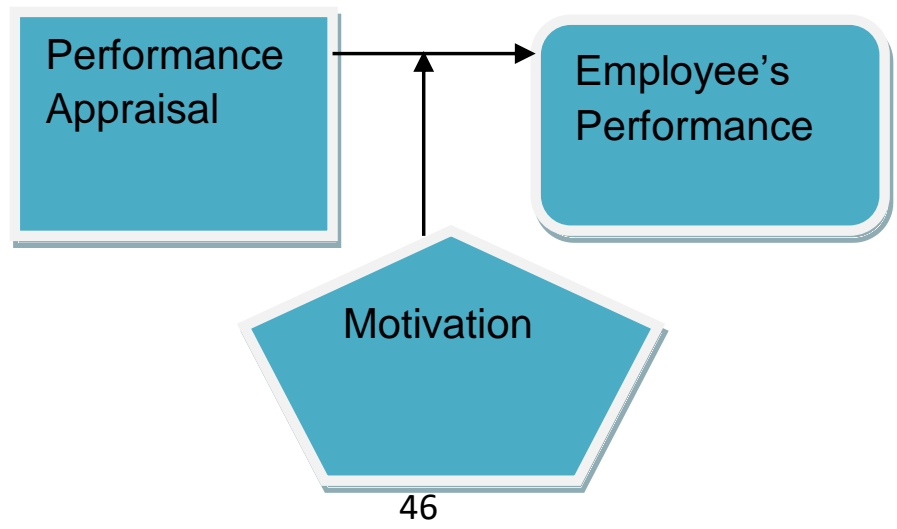




\section{Methodology}

Methodological methods and methods of observation analysis are an important part of social and commercial research. Qualifications, reliability and accuracy of analytical analysis depend on the scientific method. Quantitative research technology has been collected and analyzed. To demonstrate the hypothesis of the present application, a quantitative method is used. To achieve this goal, well-organized methods that express the characteristics of the population must determine fluctuations and predict the causal relationship between the variables used. In general, the variables are measured numerically in this method, and the search signal remains unchanged during the search process. In addition, quantitative methods have the capacity for expansion, while qualitative methods have limited generalization. Current research has been conducted in the textile industry in Faisalabad. Practical sampling techniques were used to obtain the sample. In the first phase, Masood Textile Mill (MTM) was randomly selected. As a target group, we focus on workers in the Pakistani textile industry in Faisalabad. In the second phase, a sample of 204 employees was taken, which worked well. In addition, the data was collected through a questionnaire. The collected data was analyzed using SPSS and correlation and regression analyzes were used. To check the qualifications of a researcher, reliability statistics have been used.

\section{Results and Discussion}

The analysis and interpretation of data is the main part of the research. Without these phases, generalization and prediction cannot be achieved, which is the goal of scientific research. Generalization and reasoning are based on the respondents' characteristics and attitudes.

Table 1: Mean and Standard Deviation of variables of the survey

\begin{tabular}{|l|c|c|}
\hline Variables & Mean & Standard Deviation \\
\hline Performance Appraisal & 2.2078 & 0.50775 \\
\hline Employee's Performance & 2.2084 & 0.49651 \\
\hline Motivation & 2.2362 & 0.46559 \\
\hline
\end{tabular}

Table 1 shows the distribution of the variables relative to the mean and standard deviation. The mean and standard deviation value indicates that the mean value of the variable is greater than the standard deviation. It emphasizes that data is close to the average and there is less data loss. So we can say that there is less variation between the data, so it's good in nature and the chances for errors are very low.

Table 2: Correlation Matrix of the variable

\begin{tabular}{|l|c|c|c|}
\hline Variables & Performance Appraisal & $\begin{array}{c}\text { Employee's } \\
\text { Performance }\end{array}$ & Motivation \\
\hline Performance Appraisal & 1 & 0.313 & 0.623 \\
\hline Employee's Performance & 0.220 & 1 & 0.413 \\
\hline Motivation & 0.623 & 0.321 & 1 \\
\hline
\end{tabular}

Table 2 illustrates the consequence of the correlation and indicates the strength of the motive the relationship between performance evaluation and employee performance (sig $=.000, r=.321$ ) predictors mutually evaluate and motivate performance. The calculation after the discovery output analysis of the consistent regression variable. Via the beta it is possible to compare the variables between them. The reliability of the performance evaluation and the impact of motivation also follow the positive condition for the questionnaire fulfilment of the sustainability criteria. He noted that performance assessment has a direct 
influence (.313) on employee performance, while the combined impact of motivation is positive and significant (.245).

\section{Regression Analysis}

Simple linear regression was applied to check the association between dependent and independent variables.

Table 3: Regression Matrix of the variables

\begin{tabular}{cccc}
\hline & \multicolumn{3}{c}{ EP } \\
\hline Predictors & $\mathbf{R}^{2}$ & B & P-Value \\
Main Effects & & & \\
PA & 0.057 & 0.221 & 0.032 \\
\hline
\end{tabular}

Table 3 indicates that $\mathrm{R} 2=0.057$, which means that $4 \%$ change in employee performance due to performance evaluation and the rest is due to the other factors that are checked and not included in the model. $\mathrm{B}=0.221$ means that a change in the unit in performance evaluation led to an average of 0.216 variation units in employee performance and the value of beta is little significant at $\mathrm{P}=0.032$, indicating that hypothesis 1 is acceptable for a relationship between performance evaluation and employee performance. After simple regression analysis, the researcher focuses on the moderator's effect on the variables. For this purpose, a hierarchical regression analysis was used to verify the moderator effect.

Table 4: Impact of the moderator variable

\begin{tabular}{cccc}
\hline Model & $\mathbf{R}^{2}$ & $\mathbf{R}^{2}$ Change & p-value \\
\hline 1 & 0.057 & 0.057 & 0.032 \\
2 & 0.166 & 0.109 & 0.000 \\
\hline
\end{tabular}

Table 4 presents the moderation analysis. This is the second step in the model, where regression was again checked with the addition of the interaction concept in the model. The output in the model overview (2) showed that the predictor (performance assessment) and the interaction time confirmed a significant variation in employee performance, confirming the full moderation, where the change in $R 2=0.109, p<0.001$ As a result, $\mathrm{H} 2$ accepts. Which means "Motivation reduces the relationship between performance evaluation and employee performance"

\section{Conclusion}

The essential principles of the evaluation system have improved the employee's duties, which are the basic prerequisites for organizational success in achieving the goals at a given time. The performance assessment system has effectively detected people and acknowledges that the employee is an important condemnation in the organization. Motivating employees through this system are a positive result. Continued efforts and coherence with the work have created wealth for the organization. Every department of industry staff will promote knowledge about assessment and motivation. If the textile industry in Faisalabad uses the performance evaluation of the strategic approach and combines it with human resource management and business rule, it can promote employee competence, motivation and job responsibility. The Faisalabad industry is the most important textile industry in Pakistan. If a worker's work works well and satisfies it, it also affects the Pakistani economy. 


\section{References}

Ali, S. B., Mahdi, A., \& Malihe, J. (2012). The effect of employees' performance appraisal procedure on their intrinsic motivation. International Journal of Academic Research in Business and Social Sciences, 2(12), 161.

Asiabar, A. S., Biglar, M., Manesh, P. A., \& Moslehi, S. (2013). Job Satisfaction And Development Of A Human Resource Management Policy. STRATEGIC MANAGERIAL, 27.

Barrick, M. R., \& Mount, M. K. (1991). The big five personality dimensions and job performance: a meta-analysis. Personnel Psychology, 44(1), 1-26.

Boachie-Mensah, F., \& Dogbe, O. D. (2011). Performance-Based pay as a motivational tool for achieving organisational performance: an exploratory case study. International Journal of Business and Management, 6(12), 270.

Bowen, D. E., \& Ostroff, C. (2004). Understanding HRM-firm performance linkages: The role of the "strength" of the HRM system. Academy of Management Review, 29(2), 203-221.

Campbell, D. J., Campbell, K. M., \& Chia, H.-B. (1998). Merit pay, performance appraisal, and individual motivation: An analysis and alternative. Human Resource Management (1986-1998), 37(2), 131.

Cawley, B. D., Keeping, L. M., \& Levy, P. E. (1998). Participation in the performance appraisal process and employee reactions: A meta-analytic review of field investigations. Journal of Applied Psychology, 83(4), 615.

Combs, J., Liu, Y., Hall, A., \& Ketchen, D. (2006). How much do high-performance work practices matter? A meta-analysis of their effects on organizational performance. Personnel Psychology, 59(3), 501-528.

DeNisi, A. S., \& Pritchard, R. D. (2006). Performance appraisal, performance management and improving individual performance: A motivational framework. management and Organization Review, 2(2), 253277.

DiSanza, J. R., \& Legge, N. J. (2016). Business and professional communication: Plans, processes, and performance: Pearson.

Elicker, J. D., Levy, P. E., \& Hall, R. J. (2006). The role of leader-member exchange in the performance appraisal process. Journal of management, 32(4), 531-551.

Grubb, T. (2007). Performance appraisal reappraised: It's not all positive. Journal of Human Resources Education, 1(1), 1-22.

Güngör, P. (2011). The relationship between reward management system and employee performance with the mediating role of motivation: A quantitative study on global banks. Procedia-Social and Behavioral Sciences, 24, 1510-1520.

Harris, M. M. (1994). Rater motivation in the performance appraisal context: A theoretical framework. Journal of management, 20(4), 735-756.

Honey, P. (2001). E-learning: a performance appraisal and some suggestions for improvement. The learning organization, 8(5), 200-203.

Iqbal, N., Ahmad, N., Haider, Z., \& Batool, Y. (2013). Impact of performance appraisal on employee's performance involving the Moderating Role of Motivation. Arabian Journal of Business and Management Review (OMAN Chapter), 3(1), 37.

Jabeen, M. (2011). Impact of performance appraisal on employees motivation. European Journal of Business and Management, 3(4), 197-204.

Judge, T. A., \& Ilies, R. (2002). Relationship of personality to performance motivation: A meta-analytic review. Journal of Applied Psychology, 87(4), 797.

Judge, T. A., Thoresen, C. J., Bono, J. E., \& Patton, G. K. (2001). The job satisfaction-job performance relationship: A qualitative and quantitative review. Psychological Bulletin, 127(3), 376.

Kline, T. J., \& Sulsky, L. M. (2009). Measurement and assessment issues in performance appraisal. Canadian Psychology/Psychologie canadienne, 50(3), 161.

Levy, P. E., \& Williams, J. R. (2004). The social context of performance appraisal: A review and framework for the future. Journal of management, 30(6), 881-905.

Mani, B. G. (2002). Performance appraisal systems, productivity, and motivation: A case study. Public Personnel Management, 31(2), 141-159.

Oraman, Y., Unakitan, G., \& Selen, U. (2011). Measuring employee expectations in a strategic human resource management research: Job satisfaction. Procedia-Social and Behavioral Sciences, 24, 413-420. 
Renwick, D. W., Redman, T., \& Maguire, S. (2013). Green human resource management: A review and research agenda. International journal of management reviews, 15(1), 1-14.

Taticchi, P., Tonelli, F., \& Cagnazzo, L. (2010). Performance measurement and management: a literature review and a research agenda. Measuring business excellence, 14(1), 4-18.

William, A. N. (2010). Employee motivation and performance. Unpublished dissertation). Mikkeli University of Applied Science, Finland.

Willis-Shattuck, M., Bidwell, P., Thomas, S., Wyness, L., Blaauw, D., \& Ditlopo, P. (2008). Motivation and retention of health workers in developing countries: a systematic review. BMC health services research, 8(1), 247. 